
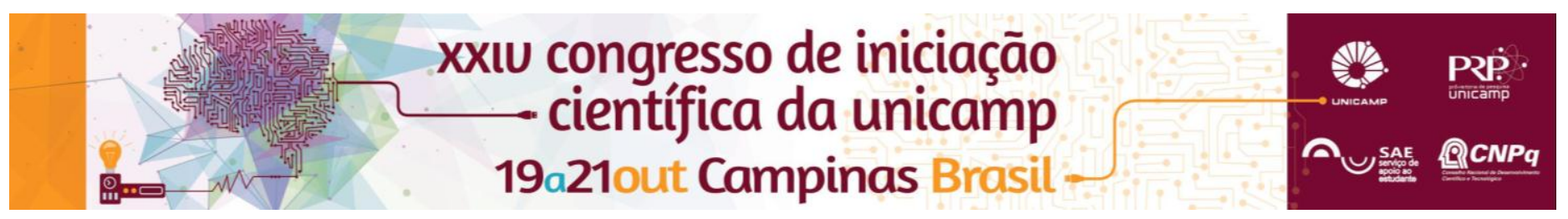

\title{
Análise e caracterização de repelentes de uso tópico.
}

\author{
Jessica T. M. Maruyama *, Rodrigo R. Catharino, Diogo Oliveira.
}

\section{Resumo}

Com o objetivo de analisar componentes e a degradação térmica de repelentes de uso tópico, foram utilizadas diferentes tipos e marcas de repelentes para assim traçar o perfil qualitativo dos mesmos e observar seu comportamento diante a exposição ao calor em diferentes tempos (30min, $60 \mathrm{~min}, 90 \mathrm{~min}$ e 24 horas). Para tal finalidade, foi utilizada a metodologia analítica de espectrometria de massas de alta resolução (HRMS).

\section{Palavras-chave:}

Espectrometria de massas; icaridina; dietiltoluamida.

\section{Introdução}

Em todo o mundo, por ano, mais de 700 milhões de pessoas são vítimas de doenças transmitidas por mosquitos, e um em cada 17 pessoas dos indivíduos infectados, são vítimas fatais ${ }^{[1]}$. Atualmente o Brasil sofreu um grande surto de dengue, e neste momento, vem sofrendo com a poderosa Zika vírus transmitido também pela picada do Aedes.

Repelentes são substâncias químicas que quando aplicadas a pele, superfícies ou roupas, fazem com que insetos sejam repelidos. A dietiltoluamida (DEET) é hoje em dia, o ingrediente ativo mais utilizado em repelentes Já a icaridina é esteticamente mais aceitável, já que não possui um forte odor, é pouco gorduroso, além de não ter apresentado reações adversas tóxicas em estudos realizados com animais ${ }^{[4]}$. Já com relação ao tempo de duração do efeito do repelente, a icaridina se mostra mais eficiente, uma vez que com apenas um aplique, ela consiga proteger o indivíduo de oito a dez horas em concentrações acima de $20 \%{ }^{[5]}$.

Nesse contexto, no presente trabalho, serão caracterizados e analisados diferentes tipos e marcas de repelentes tópicos para traçar o perfil qualitativo dos repelentes e também realizaremos a análise de degradação térmica. Para tal finalidade, foi utilizada a metodologia analítica de espectrometria de massas de alta resolução (HRMS), neste caso o equipamento utilizado será o Orbitrap (Thermo Scientific, Bremen, Alemanha)

\section{Resultados e Discussão}

Analisando os componentes de ambos os repelentes, notou-se a icaridina e a dietiltoluamida como os principais componentes ativos do repelente, já que o resultado obtido pela analise realizada no espectrômetro de massas mostrou um sinal de 229 correspondente a massa molar da icaridina na amostra de um repelente e o sinal de 191 correspondendo a massa molar da dietiltoluamida na amostra do segundo repelente.

Partindo para análise da degradação térmica dos repelentes, as amostras foram colocadas em banho maria a $50^{\circ} \mathrm{C}$ por $30,60,90$ minutos e 24 horas. Após cada tempo, era preparada a solução para injeção no espectrômetro de massas.

Todas as soluções foram injetadas no espectrômetro de massas, sendo que as que continham ácido fórmico, analisadas por ionização em modo negativo e as que continham hidróxido de amônio em modo positivo.
Os resultados das análises em modo negativo apresentaram um interferente não identificado e o componente ativo não foi identificado, portanto os resultados foram descartados já que as análises em modo positivo foram eficazes.

Observando os resultados obtidos, a degradação do composto ativo se mostrou presente apenas nas amostras que foram expostas ao calor por 24 horas, tanto a icaridina como também a dietiltoluamida.

\section{Conclusões}

Diante a todos os resultados obtidos, observou se que os componentes ativos de ambos os repelentes são as principais substâncias presentes em sua formulação e sua degradação frente ao calor de $50^{\circ} \mathrm{C}$ ocorreu apenas com a sua exposição durante 24 horas em banho maria.

\section{Agradecimentos}

Agradecimentos ao orientador Prof. Dr. Rodrigo Ramos Catharino; Co orientador Diogo Oliveira e ao Laboratório INNOVARE de Biomarcadores, localizado no Núcleo de Medicina e Cirurgia Experimental da Faculdade de Ciências Médicas da Universidade Estadual de Campinas.

${ }^{1}$ Fradin MS. Mosquitoes and mosquito repellents: a clinician's guide. Ann Int Med. vol.128: p.931-40, 1998

2 ANVISA - Resolução RDC 19/2013 - Requisitos para concessão de registro de repelentes de insetos.

3 Roey K.V., Sokny M., Denis L., Broeck N. V., Heng S., Siv S., Sluydts V., Sochantha V., Coosemans M.,Durnez N. Field Evaluation of Picaridin Repellents Reveals

Differences in Repellent Sensitivity between Southeast Asian Vectors of Malaria and Arboviruses., vol.8, N12, p3326, December 2014

${ }^{4}$ Lupi E., Hatz C., Schlagenhauf P.The efficacy of repellents against Aedes, Anopheles, Culex and Ixodes spp.Travel Medicine and Infectious Disease, vol11, p374e411, 2013

5 Katz T. M, Miller J.H., Hebert A.A, Insect repellents: Historical perspectives and new developments. J AM ACAD DERMATOL, Houston, Texas, vol 58, N5. 